\title{
Progesterone Treatment Experience in a Patient with Lymphangioleiomyomatosis Presenting with Recurrent Pneumothorax
}

\author{
Baykal Tülek, Fikret Kanat, Mecit Süerdem \\ Department of Chest Disesases, Selçuk University Faculty of Medicine, Konya
}

\begin{abstract}
Lymphangioleiomyomatosis (LAM) is a rare interstitial lung disease. Patients with LAM generally present with dyspnea and spontaneous pneumothorax. Today, while there is no proven medical treatment method for LAM, progesterone is among the widely used drugs. In this report, the effect of approximately l year of progesterone treatment in a patient with LAM, presenting with recurrent pneumothorax, was evaluated.
\end{abstract}

Keywords: Lymphangioleiomyomatosis, pneumothorax, progesterone treatment

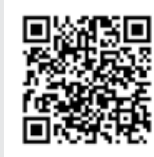

Received Date: 03.07.2012

Accepted Date: 03.11 .2012

Available Online Date: 27.10.2014

Address for correspondence

Baykal Tülek, Department of Chest Diseases, Selçuk

University Faculty of Medicine, Konya, Turkey

E-mail: baykaltulek@yahoo.com

(C) Copyright 2014 Turkish Respiratory Society (TRS) Eurasian J Pulmonol 2014

DOI: 10.5152/ejp.2014.28863

- Available online at www.eurasianjpulmonol.com

\section{INTRODUCTION}

Lymphangioleiomyomatosis (LAM) is a rare interstitial lung disease, the etiology of which is unknown, affecting mostly women of child-bearing age (1). In this disease, diffuse proliferation of smooth muscle cells is observed microscopically. It may be seen in association with sporadic or tuberous sclerosis complex (TSC). Although its pathogenesis is not completely known, it is thought that estrogen has an important role in the progression of the disease due to its not occurring before menarche, its acceleration in pregnancy, its slowing down after oophorectomy, and the very rare occurrence in post-menopause (2). Although positive outcomes have been reported with progesterone and sirolimus treatment, there is no definite treatment for LAM. In this report, the effect of approximately 1 year of progesterone treatment in a case having renal angiomyolipoma with LAM, presenting with recurrent pneumothorax, was evaluated.

\section{CASE PRESENTATION}

A 19-year-old female patient was admitted to our clinic with complaints of sudden shortness of breath and acute chest pain that began 2 days ago. It was learned from the history of the patient that she had a complaint of dyspnea on exertion for the last 2 years, she applied to a hospital with sudden chest pain complaint almost 4 months ago, and she underwent a tube thoracostomy, with a diagnosis of pneumothorax in the right lung. No pathological finding was detected in the physical examination, except a respiratory sound decrease in the right hemithorax. Tube drainage was applied to the patient on detection of the pneumothorax on the right by chest radiography. Thin-walled air cysts, diffused in both hemithoraces with diameters varying between 2 and $10 \mathrm{~mm}$, were determined in the patient's thorax by high-resolution computerized tomography (HRCT) (Figure 1a). As a result of the diagnostic thoracoscopic lung biopsy, a diagnosis of LAM was made. Although no feature was detected in magnetic resonance imaging of the brain from the screening examinations of the patient, a tumoral lesion compatible with angiomyolipoma (AML) having a diameter of $3.5 \mathrm{~cm}$ in the left kidney abdomen CT was found (Figure $1 \mathrm{~b}$ ). Therefore, the patient consulted with an interventional radiology unit with respect to embolization; however, an ultrasonography follow-up at 6-month intervals was recommended, since the lesion was smaller than $4 \mathrm{~cm}$. Monthly progesterone ( $400 \mathrm{mg}$ IM) treatment was initiated to the clinically stabilized and pleurodesis-applied patient with talc, whose pneumothorax regressed 

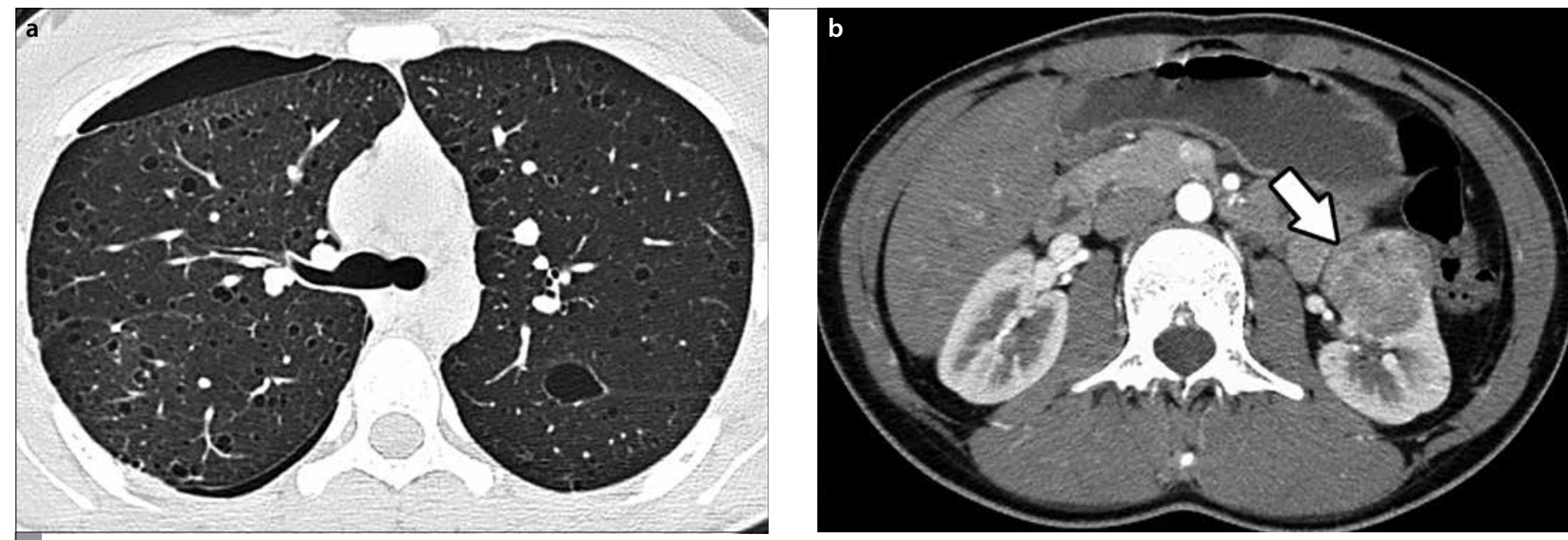

Figure 1.a, b. Pneumothorax in the right lung and cystic lesions having diffuse thin walls in both lungs in thorax high-resolution computerized tomography (a); angiomyolipoma in the left kidney in the abdominal CT (white arrow) (b)

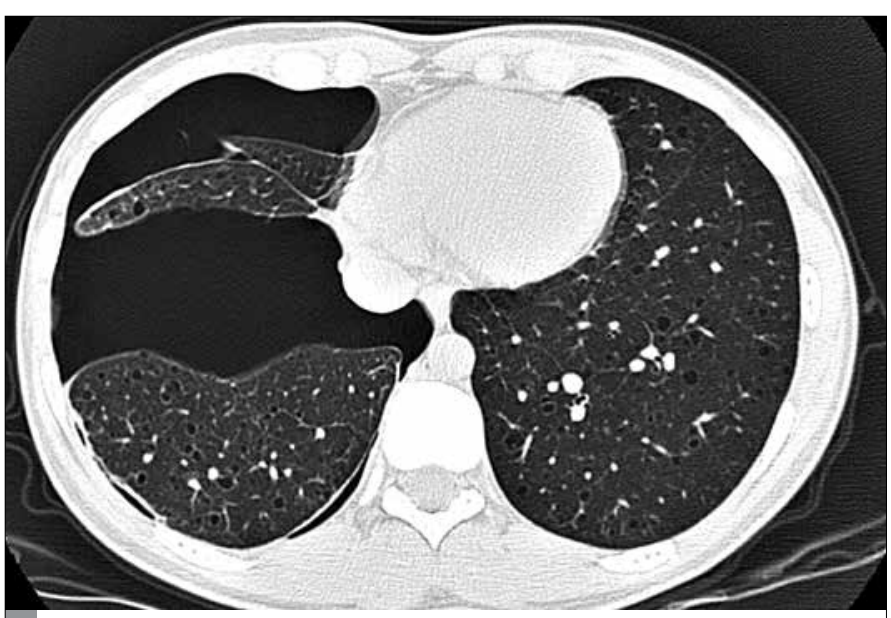

Figure 2. Pneumothorax in the right basal hemithorax and two-sided cystic lesions having thin walls in thorax high-resolution computerized tomography

completely after tube drainage. There was no significant regression of the patient's exertional dyspnea in the follow-ups at 3-month intervals. Forced vital capacity over the expected predicted values of pulmonary function tests was $86 \%, 82 \%$, and $80 \%$, and forced expiratory volume in 1 second was $84 \%, 81 \%$, and $80 \%$, respectively. In the same controls, decline of $48 \%, 46 \%$, and $40 \%$ were observed, respectively, in carbon monoxide diffusion capacity of the lung. The patient applied to the emergency service with a complaint of right chest pain in the 11th month of the treatment. With the detection of pneumothorax in the subzone of the right lung in the chest radiography and thorax HRCT, tube drainage and pleurodesis were applied to the patient (Figure 2). When the present findings were evaluated, we decided to discontinue the treatment, considering that a positive response could not be obtained with progesterone treatment in the patient.

\section{DISCUSSION}

Lymphangioleiomyomatosis is a rare disease characterized by the proliferation of abnormal smooth muscle cells in the lungs and lymphatic system (1). Dyspnea and spontaneous pneumothorax are the typical presenting symptoms and findings, as in our case. Pneumothorax occurs during application in almost $40 \%$ of patients and in
$66 \%$ of patients at any time in the disease process $(3,4)$. Pneumothorax recurrences are identified in $75 \%$ of patients, as in our case (5). Apart from this, chylothorax, acid, hemoptysis, and abdominal AMLs, particularly in the kidneys, may be detected during application.

Lymphangioleiomyomatosis is usually seen in premenopausal women, as in our case (2). It may be sporadic or TSC-associated. Mental retardation, epileptic seizures, and sebaceous adenomas constitute the classical triad of TSC; however, these findings were not present in our patient.

Although chest radiography may be normal in $20 \%$ of the cases, there may also be patients, as in our case, presenting with spontaneous pneumothorax, and this condition is helpful for the diagnosis. Apart from that, diffuse, bilateral reticular opacities and hyperinflation findings may be detected in the chest radiographies of cases with LAM (6). The primary imaging method recommended for the diagnosis, evaluation, and follow-up is thorax HRCT. Air cysts having diameters of 2-5 $\mathrm{mm}$ in general that are diffused in both lungs and surrounded by normal parenchyma are typical HRCT findings. The diameters of the cysts may be up to $30 \mathrm{~mm}$ (1). Cystic pulmonary diseases, such as emphysema, Langerhans cell pulmonary histiocytosis, lymphocytic interstitial pneumonia, and Birt-Hogg-Dube syndrome, have to be considered in the differential diagnosis (6).

The diagnostic criteria for lymphangioleiomyomatosis were published by the European Respiratory Society (ERS) study group in 2010 (Table 1) (1). The golden standards for the diagnosis are pathological findings compatible with LAM. However, characteristic HRCT findings with $A M L$ or other characteristic LAM findings may eliminate the biopsy requirement. Elimination of diseases in the radiological differential diagnosis is important for LAM diagnosis.

Renal AML and meningioma risks are increased in patients with LAM. Due to the detection of abnormal findings with abdominal imaging methods in almost two-thirds of patients with lymphangioleiomyomatosis, routine computed tomography examination is recommended for these patients (7). Renal AMLs may get larger in time and carry the risk of bleeding, especially when their sizes are larger than $4 \mathrm{~cm}$. Therefore, if there is no bleeding in AMLs smaller than $4 \mathrm{~cm}$, a yearly follow-up with ultrasonography is suggested. However, if the AML 
Table 1. European Respiratory Society Lymphangioleiomyomatosis (LAM) diagnostic criteria

\section{Definite LAM}

1. Characteristic ${ }^{1}$ or compatible ${ }^{2}$ HRCT findings and LAM compatible pathologic findings

OR

2. One from below with characteristic ${ }^{1} \mathrm{HRCT}$ Angiomyolipoma (kidney) ${ }^{3}$

Thoracic or abdominal cheilosis effusion ${ }^{4}$

Lymphangioleiomyoma ${ }^{5}$ or lymph node having LAM involvement ${ }^{5}$

Definite or probable TSC

\section{Probable LAM}

1. Characteristic ${ }^{1}$ HRCT and compatible clinical history ${ }^{6}$ OR

2. Compatible ${ }^{2} \mathrm{HRCT}$ and one from below Angiomyolipoma (kidney) ${ }^{3}$

Thoracic or abdominal cheilosis effusion ${ }^{4}$

\section{LAM having low probability}

1. Characteristic ${ }^{1}$ or compatible ${ }^{2} \mathrm{HRCT}$ findings

${ }^{1}$ : Multiple (>10) round, thin-walled air cysts; ${ }^{2}$ : a few (between 2 and 10 ) air cysts; ${ }^{3}$ : diagnosed with typical computed tomography findings or pathology; ${ }^{4}$ : in line with inspection of the effusion and/or biochemical findings; ${ }^{5}$ : in line with pathologic evaluation; ${ }^{6}$ : involves compatible clinical features pneumothorax, ${ }^{9}$ especially multiple and/or bilateral and pulmonary function tests compatible with LAM.

HRCT: high-resolution computerized tomography; LAM: lymphangioleiomyomatosis; TSC: tuberous sclerosis

size is larger than $4 \mathrm{~cm}$ or the diameters of the renal aneurysms are greater than $5 \mathrm{~mm}$, embolization in elective conditions or renal protective surgery alternatives are recommended due to the high bleeding risk. In the case of urinary system bleeding, these two treatment alternatives, primarily embolization, are recommended (1).

Due to the fact that the AML size was very close to $4 \mathrm{~cm}, 6$-month follow-ups were planned, and no increase in size and/or bleeding during the follow-ups was detected. Brain magnetic resonance imaging (MRI) examination for the purpose of meningioma and tuberous sclerosis screening is a scanning method that is recommended for patients with LAM. Brain MRI examination is particularly important, due to the possibility of meningioma enlargement with this treatment, in patients who are to use progesterone therapy, as in our case (1).

There is no definite treatment for lymphangioleiomyomatosis; however, positive results are reported with progesterone and mTOR inhibitors (1). Although progesterone treatment is widely used (8), there is no placebo-controlled randomized study that has been carried out with progesterone. After the first successful progesterone treatment experience in a patient with LAM by McCarty et al. (9) in 1980, positive results have been reported in LAM treatment with progesterone in different case reports. In a retrospective study, statistically insignificant contributions were displayed on forced expiratory volume in 1 second after progesterone treatment, and significant positive contributions were displayed on carbon monoxide diffusion capacity (10). However, in the retrospective study of Taveira-DaSilva et al. (11), it was found that progesterone given orally or intramuscularly did not have a positive effect on respiratory function. In the current international guidelines, 12-month progesterone trial therapy is recommended for patients with LAM, and it is stated that it is necessary to discontinue the treatment if there is no positive contribution detected on respiratory functions and symptoms. A slight fall in respiratory functions of our patient with almost 1 year of progesterone treatment was observed, in line with these recommendations; however, progesterone therapy was ended with the patient's presentation of pneumothorax. Although there are cases in which positive results have been obtained, the fact that positive results are usually reported in case reports has to be taken into consideration.
Lung transplantation is a treatment alternative that provides highly important contributions to the survival of patients with LAM (12). Due to the low number of patients, although the issue of which patients are candidates for transplantation is not clear, it is recommended that lung transplantation be considered for patients below the age of 65 , those in functional classes 3 and 4 in the New York Heart Association classification, and those having serious deterioration in respiratory functions and exercise capacity (1).

\section{CONCLUSION}

Consequently, HRCT is an important imaging method in patients presenting with recurrent pneumothorax for the differential diagnosis. When typical HRCT findings are present, particularly in women of childbearing age, a diagnosis of LAM has to be taken into consideration. Prospective controlled studies are required for the evaluation of effective medical treatment alternatives in these patients.

Informed Consent: Due to the retrospective design of the study, informed consent was not taken.

Peer-review: Externally peer-reviewed.

Author contributions: Concept - B.T.; Design - B.T; Supervision -B.T.; Resource - B.T., F.K.; Materials - B.T., M.S.; Data Collection and/or Processing - B.T.; Analysis and/or Interpretation - B.T.; Literature Review - B.T.; Writing - B.T; Critical Review - F.K., M.S.

Conflict of Interest: No conflict of interest was declared by the authors.

Financial Disclosure: The authors declared that this study has received no financial support.

\section{REFERENCES}

1. Johnson SR, Cordier JF, Lazor R, Cottin V, Costabel U, Harari S, et al. European Respiratory Society guidelines for the diagnosis and management of lymphangioleiomyomatosis. Eur Respir J 2010; 35: 14-26. [CrossRef]

2. Ohori NP, Yousem SA, Sonmez-Alpan E, Colby TV. Estrogen and progesterone receptors in lymphangioleiomyomatosis, epithelioid hemangioendothelioma, and sclerosing hemangioma of the lung. Am J Clin Pathol 1991; 96: 529-35.

3. Almoosa KF, Ryu JH, Mendez J, Huggins JT, Young LR, Sullivan EJ, et al. Management of pneumothorax in lymphangioleiomyomatosis: effects on recurrence and lung transplantation complications. Chest 2006; 129: 1274-81. [CrossRef]

4. Johnson SR, Tattersfield AE. Clinical experience of lymphangioleiomyomatosis in the UK. Thorax 2000; 55: 1052-7. [CrossRef] 
5. Steagall WK, Glasgow CG, Hathaway OM, Avila NA, Taveira-Dasilva AM, Rabel A, et al. Genetic and morphologic determinants of pneumothorax in lymphangioleiomyomatosis. Am J Physiol Lung Cell Mol Physiol 2007; 293: L800-8. [CrossRef]

6. Brant S, Parker MS, Brath LK, Grimes MM. A 47-year-old woman with progressive dyspnea and recurrent pneumothoraces. Chest 2009; 135: 1389-94. [CrossRef]

7. Avila NA, Kelly JA, Chu SC, Dwyer AJ, Moss J. Lymphangioleiomyomatosis: abdominopelvic CT and US findings. Radiology 2000; 216: 147-53. [CrossRef]

8. Ryu JH, Moss J, Beck GJ, Lee JC, Brown KK, Chapman JT, et al. The NHLBI lymphangioleiomyomatosis registry: characteristics of 230 patients at enrollment. Am J Respir Crit Care Med 2006; 173: 105-11. [CrossRef]
9. McCarty KS Jr, Mossler JA, McLelland R, Sieker HO. Pulmonary lymphangiomyomatosis responsive to progesterone. N Engl J Med 1980; 303: 1461-5. [CrossRef]

10. Johnson SR, Tattersfield AE. Decline in lung function in lymphangioleiomyomatosis: relation to menopause and progesterone treatment. Am J Respir Crit Care Med 1999; 160: 628-33. [CrossRef]

11. Taveira-DaSilva AM, Stylianou MP, Hedin CJ, Hathaway O, Moss J. Decline in lung function in patients with lymphangioleiomyomatosis treated with or without progesterone. Chest 2004; 126: 1867-74. [CrossRef]

12. Kpodonu J, Massad MG, Chaer RA, Caines A, Evans A, Snow NJ, et al. The US experience with lung transplantation for pulmonary lymphangioleiomyomatosis. J Heart Lung Transplant 2005; 24: 1247-53. [CrossRef] 